MODELING, IDENTIFICATION AND CONTROL, 1984, VOL. 5, NO. 3, 151-170

doi:10.4173/mic.1984.3.3

\title{
Robotics research in Norway
}

\section{J. R. HØIFØDT, T. WETLESEN and H. HÅKONSEN}

Keywords: robotics, industrial robots, automation, robotics research

Except for some districts and industries, the population of industrial robots in Norway is low. Trallfa A/S is definitely the largest producer of robots in Norway. Jonas Øglænd A/S formerly produced handling manipulators, but they are now produced abroad. New companies such as NORKYB are developing. In addition to Trallfa and Øglænd, the development of robot systems is done by different research institutes such as the Center for Industrial Research (SI), SINTEF and the Rogaland Research Center (RF). These institutes do research work both for the robot manufacturers and directly for end users.

\section{Introduction}

Norwegian industry is dominated by companies with less than 100 employees. The automobile industry is limited to parts production and there are only a few heavy metal industries. Consequently, the population of industrial robots (IRb) in Norway is rather low. About 250 robots have been installed so far. Number of robots relative to the number of employees in industry is 5 per 10000 , while Japan has 15 per 10000 and Sweden has 30.

Nearly half of all robots are used for functions such as palletizing and transferring parts to/from other machines. Spray painting and welding are also important, each representing about $25 \%$ of the robots installed.

The furniture industry is perhaps the most robotized of the Norwegian industries with many painting robots, mostly of the Trallfa type. The first one, which was installed at Vestlandske Møbelfabrikk in Sykkylven has been painting armchairs since 1971. Today there are new applications under development to use robots for sanding wooden furniture and stapling leather onto frames. Uniformity within the furniture industry and cooperation between companies have supported automation in this section of Norwegian industry.

It is interesting to note that $30 \%$ of all robots are found within the Jæren area in the vicinity of Stavanger. This is mainly because both Trallfa and Øglænd have their manufacturing plants there, but also a result of the TESA cooperation between the metal industry companies in this area.

Research and development of industrial robots in Norway has a history of about 15 years. The aim of this paper is to give an overview of this activity by presenting some selected projects.

\section{Development of the robot industry in Norway started in the late 'sixties}

In Rogaland in the south-eastern region of Norway, originally an agricultural district, small industrial companies have grown up based mainly on light mechani-

Received 18 September 1984.

+ Center for Industrial Research (SI), Electronics Division, Forskningsvn. 1, 0314 Oslo 3, Norway. 
cal products such as agricultural machines, wheelbarrows, bicycles-typical medium or large size production. As far back as 1957 these companies combined to meet the challenge to compete with the large industrial countries on technological achievements. Low cost automation in production as well as improvement of the workers' environment were in focus. One group of companies formed TESA (technical cooperation), and another group formed the Jæren Automation Company. The latter was managed by Ole Molaug, later known as the designer of the first Trallfa robot.

The first design of the Trallfa robot was on the drawing board in 1964. The main idea was to eliminate a bottleneck in Trallfa's own production line, the spray painting of wheelbarrow trays as they passed hanging from a conveyor belt. Two years work went into making this robot, and when it was installed, it sprayed the trays as planned (Fig. 1). The idea was based on 'teach in' programming of the robot; the robot could accurately repeat the path learned from an experienced spray painter. To record the path information, a magnetic tape recorder was used and replaced in control mode. The first commercial robot was delivered to the Gustavsberg bathtub factory outside Stockholm in Sweden in 1969, and was designed to enamel bath tubs. Today Gustavsberg has 11 Trallfa robots in their production line. Since then, Trallfa has produced 1500 robots in Norway, and 300 under licence agreement with DeVilbiss, in the USA, and KOBE in Japan. Technical improvements and upgrading have taken place with a microprocessor controlled system TR3000 in 1974, and a multiprocessor system TR4000 in 1982. Features in the latest model include linear interpolation, cartesian coordinate control, vision system, and learning by manual

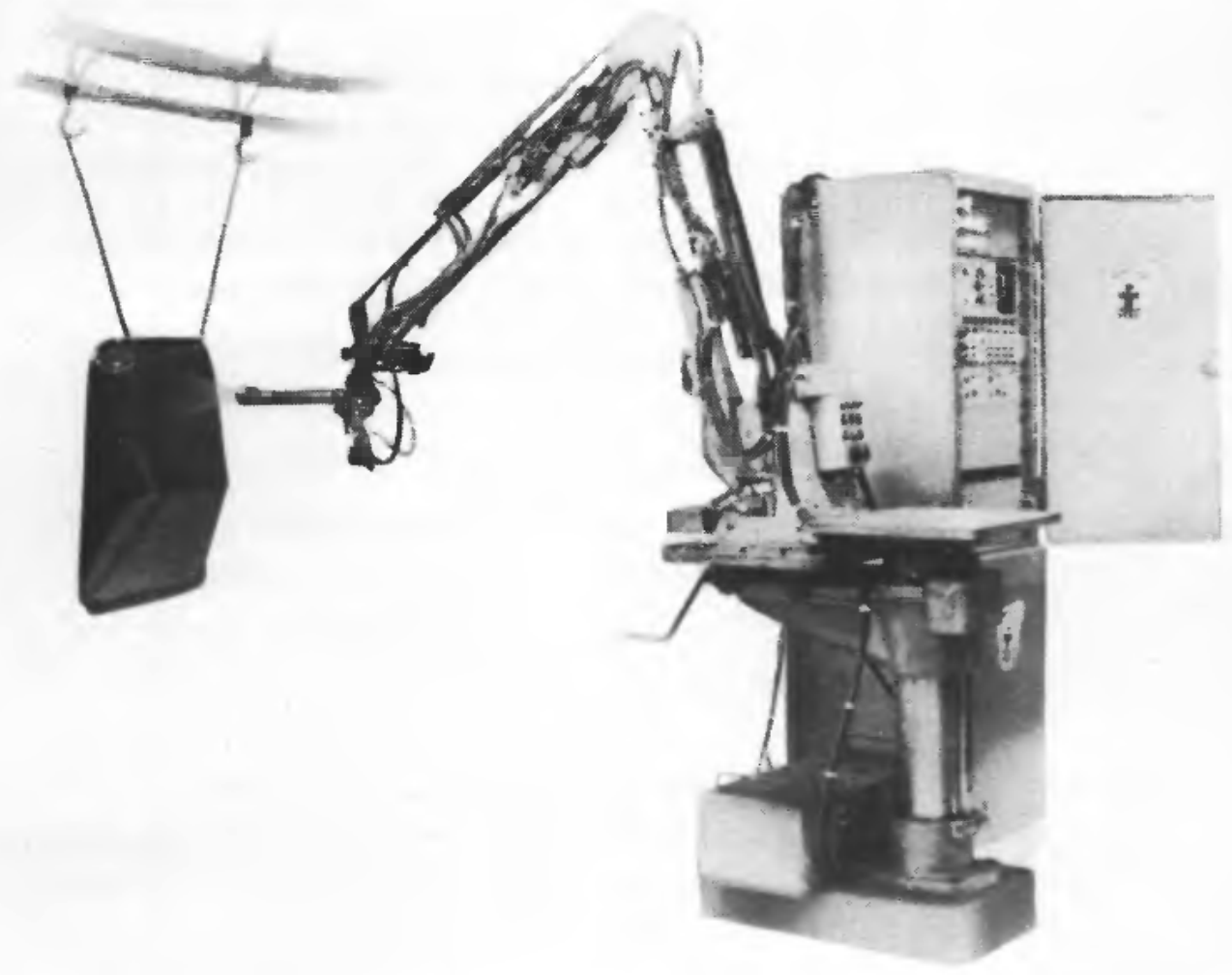

Figure 1. The first Trallfa robot designed for spray painting wheelbarrows in Trallfa's own production line. 
guidance or pushbutton control. The main applications are painting, handling, and welding.

The program memory has increased from 115 seconds on the first single cassette tape memory to two hours on discette, and now even more by using bubble memory and Winchester-disc.

While the Trallfa robot was a 'teach in' path robot, the TESA group of companies was in need of reprogrammable handling devices. In 1969 a joint development project with the Center for Industrial Research (SI) was started with the
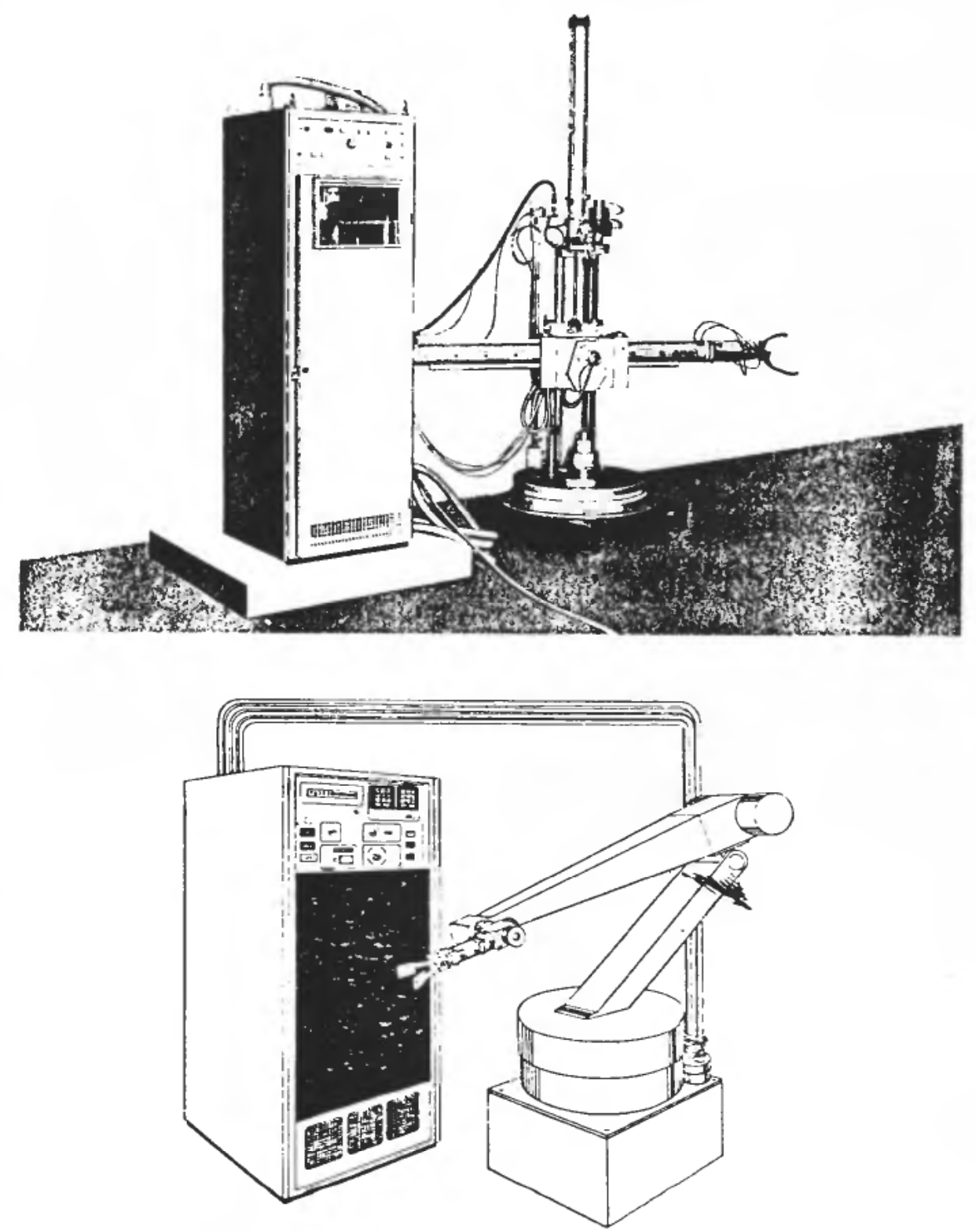

Figure 2. The TESAMAT I and II robots designed for handling work pieces (pick and place robot). 
objective of developing a 'pick and place' robot. This robot, TESAMAT I, was a cartesian robot programmed in standard EIA code on paper tape, as used on numerically controlled machines. The axis was servo controlled with either stepmotors or a DC-motor. The next robot, TESAMAT 2, was developed with programmes stored in a semiconductor memory with a capacity of 400 EIA program blocks. This robot was used at A/S Sandnes Aducerverk up to 1983.

Experience from TESAMAT I and II led to the MOVE-O-MATIC pick and place robot developed by Jonas Øglænd A/S, the leading manufacturer of bicycles in Scandinavia. This was, however, a simple pick and place robot with pneumatic motors and mechanically defined end points. These robots have been manufactured for 10 years, originally only for in-house applications. The later design has an advanced programming system for point to point control. In 1983 Øglænd arranged a licence agreement with Fairey, an English manufacturer of robots (Fig. 3).

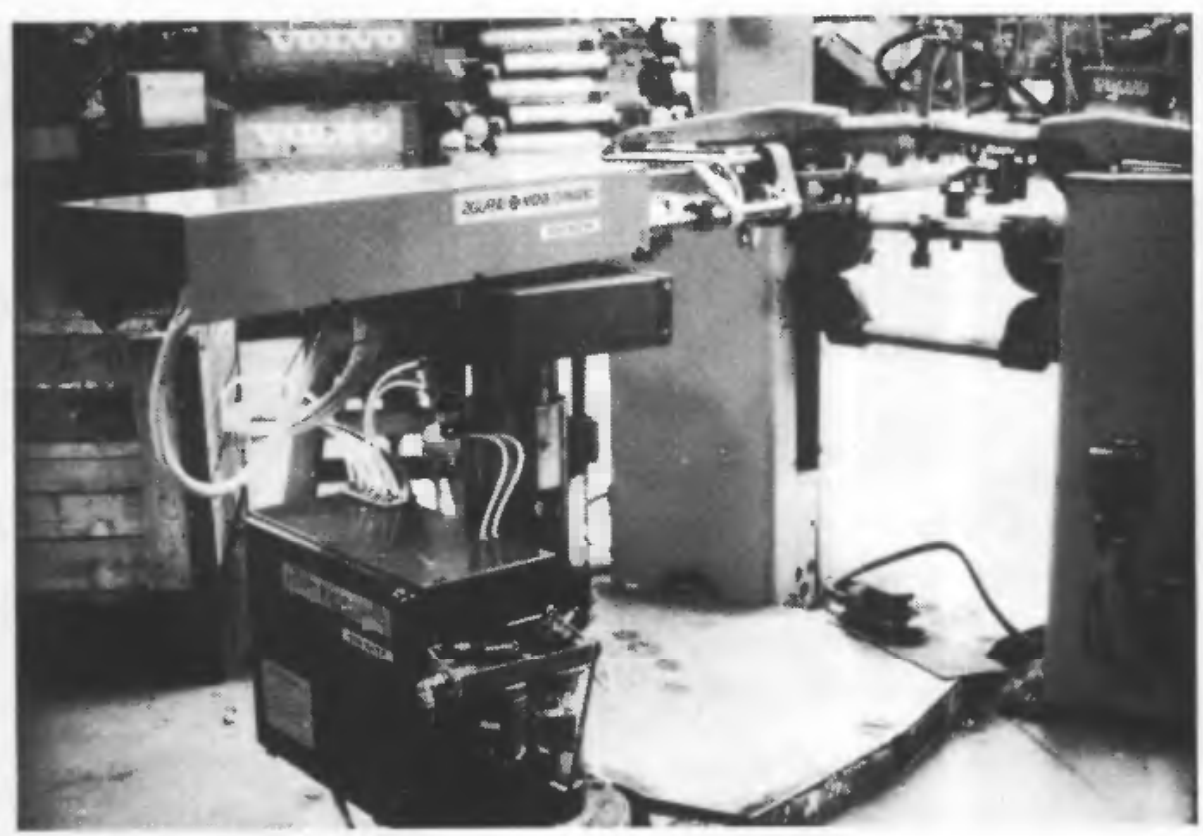

Figure 3. Pick and place robot developed and produced by Jonas Øgland A/S. Now produced and marketed under a licence agreement with Fairey, UK.

\section{Location of robotics $R \& D$ in Norway}

NTNF (The Royal Norwegian Council for Technical and Scientific Research) has been an important financial resource for R \& $D$ in robotics during the 'seventies, and will continue to be in the future. During the last decade $R \& D$ has grown in different parts of the country, and today it is dominated by SI (Central Institute for Industrial Research) in Oslo, SINTEF in Trondheim, and RF (Rogaland Research Institute) in Stavanger.

SI is a research organization associated with NTNF. The staff of 350 includes four disciplines: electronics, data processing, chemistry and materials research. Robotics research started in 1971 and since 1979 robotics has been a major activity 
in the Electronic Division. This is partly because of a close association with Trallfa $\mathrm{A} / \mathrm{S}$.

SINTEF is the largest research organization in Norway with more than 1000 employees. Some important research areas are: Control systems, data technology, electronics, physics, chemistry, oil technology, civil engineering, mechanical engineering and hydrodynamics. SINTEF is closely connected with the Norwegian Institute of Technology in Trondheim.

Rogalandsforskning is located in Stavanger near the oil activities in the western part of the country. Although oil related projects are the most important for RF, the Center for Products and System Development has several years of experience with robotic applications.

Some research is also done at the Norwegian Institute of Technology (NTH) in Trondheim and the National Center of Technology (STI) in Kongsberg west of Oslo.

\begin{tabular}{|c|c|c|c|}
\hline Institute & Location & $\begin{array}{c}\mathrm{R} \& \mathrm{D} \\
\text { man years* }\end{array}$ & R \& D, Important activities \\
\hline $\begin{array}{l}\text { Center for } \\
\text { Industrial } \\
\text { Research (SI) }\end{array}$ & Oslo & 11 & $\begin{array}{l}\text { Manipulator control } \\
\text { Man-machine communication } \\
\text { Vision systems } \\
\text { Electronics, processor technology }\end{array}$ \\
\hline SINTEF & Trondheim & 6 & $\begin{array}{l}\text { Mechanical engineering } \\
\text { Flexible manufacturing systems } \\
\text { (FMS) } \\
\text { Integrated manufacturing } \\
\text { Automatic assembly } \\
\text { Cost-benefit modeling of robot } \\
\text { installations }\end{array}$ \\
\hline $\begin{array}{l}\text { Rogaland Research } \\
\text { Institute } \\
\text { (RF) }\end{array}$ & Stavanger & 3 & $\begin{array}{l}\text { Robot applications in mechanical } \\
\text { industries } \\
\text { Automatic grinding } \\
\text { Seam tracking equipment }\end{array}$ \\
\hline $\begin{array}{l}\text { STI } \\
\text { National Center } \\
\text { of Technology }\end{array}$ & Kongsberg & $1-2$ & $\begin{array}{l}\text { Flexible manufacturing system } \\
\text { Robot welding } \\
\text { Application lab/courses }\end{array}$ \\
\hline $\begin{array}{l}\text { NTH } \\
\text { Norwegian Insti- } \\
\text { tute of Technology }\end{array}$ & Trondheim & 2 & $\begin{array}{l}\text { Control theory } \\
\text { Servos } \\
\text { Adaptive control } \\
\text { Education }\end{array}$ \\
\hline
\end{tabular}

* 1982

Figure 4. On-going activities in the main R \& D institutes in Norway. Robot manufacturers are not included.

\section{Important $R \& D$ robotic projects: an overview}

Details are given of selected $R \& D$ projects, mainly those which are carried out by research organizations such as SI, RF and SINTEF. Criteria for selecting the examples have been technological complexity, size and value for the end user. 


\subsection{Computer managed parts manufacture (SINTEF)}

The idea of the Integrated Manufacturing Cell was to automate small series production in mechanical industries by integrating a number of Numerical Controlled (NC) machines and a robot with a computer system. The time used for reprogramming the manufacturing cell could then be minimized.

The project was started in 1975 under grants from NTNF and A/S Kongsberg Våpenfabrikk. Four NC machines, a transport system and a Cincinnati robot were installed in the laboratory. All machines were interfaced to a Direct Numerical Control minicomputer which was linked to the company's mainframe.

To make the integrated machinery shop work and to be reprogrammed, the following modules had to be designed:

$\mathrm{NC}$ and CNC control of machines and IR.

Direct Numerical Control to handle machining tasks, distribution of control data, communication with external planning systems, and manipulation with control data.

Monitoring and control system to keep the operator informed and give alarm if errors occurred.

Logistics, handling and sequencing of materials.

Data storage, data logging and data retrieval.

Cooperation and communication with other data systems.

Safety system for operator and machinery.

The DNC (Direct Numerical Control) is essential in the SINTEF cell-concept. First, the DNC processes NC-data. Second, the DNC is able to read data from the NCmachines and pass these data into the mainframe computer. The communication between the robot, the NC machines and the transporter is handled by the DNC. Strategy and control of the transport system are processed in the mainframe, but control signals go through the DNC.

In Norway this manufacturing concept has been used in several automation projects in the metalworking industry. A/S Kongsberg Våpenfabrikk was one of the



Figure 5. The Direct Numerical Control (DNC) computer is the central part in the Computer Managed Parts Manufacturing concept developed at SINTEF. 




Figure 6. Drawing of the SINTEF Computer Managed Parts Manufacturing laboratory including a robot and $4 \mathrm{NC}$ machines. The transport system is shown.

pioneers and they have used the 'cell' concept in the automation of their automobile, military and turbine part production.

Late in $1983 \mathrm{KV}$ automated the precision grinding of the third and fourth stage blades of the F-16 gas turbine. Two manufacturing stations were installed, each including two grinding machines. a rinse station, a measurement station and a robot. There are seven grinding operations on each turbine blade and the machines are controlled by feedback from the position sensors in the measurement station. The project, called RAMIGO (Robotics and Automated Measuring in Grinding Operations), demonstrated that it is possible to reduce the labour costs by $66 \%$ even with a $50 \%$ increase in production. The cost reduction is due partly to higher machine utilization and partly to unmanned production. Product quality is improved.

\subsection{Flexible automatic assembly (SINTEF)}

After the completion of the manufacturing cell project, SINTEF worked with automated assembly. In their laboratory they have installed a PUMA 600 robot for test purposes. Through close contact with Norwegian companies they identify actual assembly operations which could be automated. Initial experiments to see if an assembly operation is possible, are performed in SINTEF's laboratory. When the experiments seem promising, further contact is made with the company and automation of the actual assembly process is started.

SINTEF makes an effort to reduce dead time between assembly of different products. The objective is to change the product with zero dead time of the assembly line. This is possible if new feeders and grippers can be installed before terminating the assembly of the last product. 


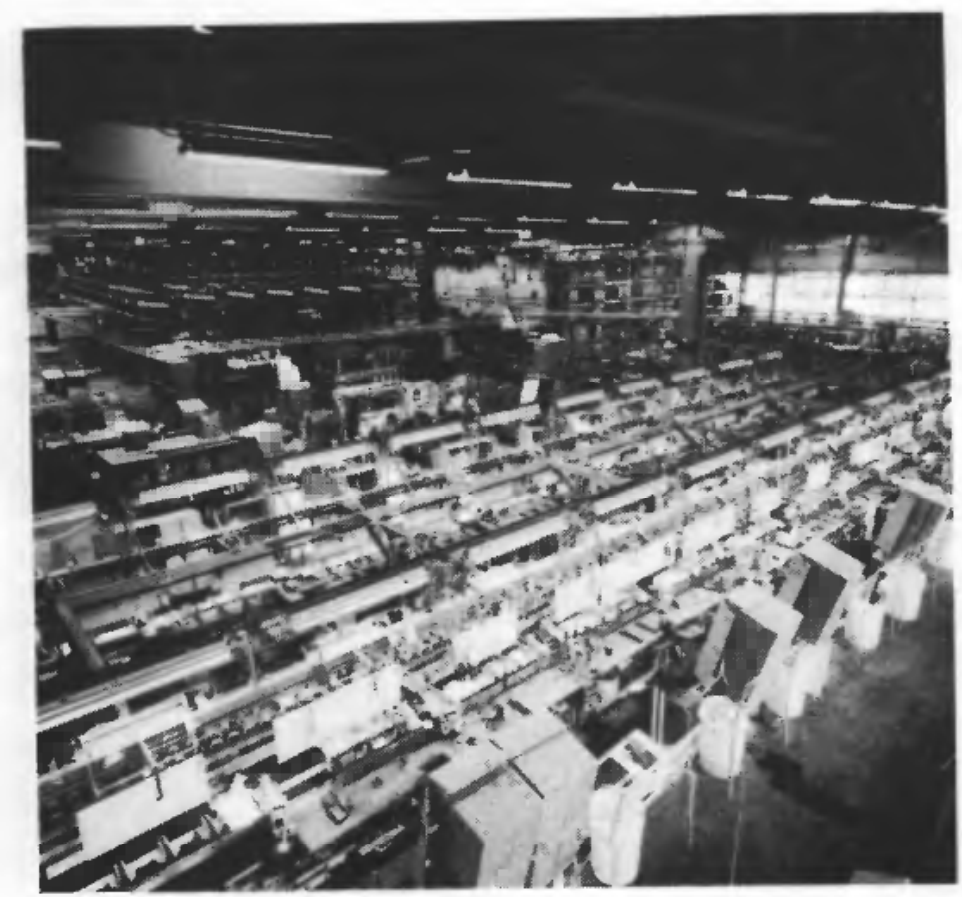

Figure 7. Automated assembly of electric heaters at NOBØ, Trondheim.

Within the end of this year SINTEF has planned to equip their assembly lab with two assembly robots, main transport system, flexible jig system, programmable magazines and part feeders, camera and other inspection equipment.

There is also work going on to make a data control system to coordinate all elements in the flexible assembly cell.

Since 1980 SINTEF has been involved with three industrial applications of automatic assembly in Norway. The first project was the automated assembly of electric heaters for the NOBØ company. Next was a similar automation at SIEMENS in Trondheim, also with electric heaters, but the degree of automation at SIEMENS is higher. The third project was in cooperation with GLAMOX, a large manufacturer of lightening equipment.

In parallel with the development of equipment and controls for automated assembly, SINTEF works intensively with cost/benefit modeling of assembly automation tasks. Productivity calculations and ROI analyses are made using models, in order to minimize the risk of any automation project that is planned.

\subsection{Grinding of plough-bodies $(R F)$}

Rogaland Research Institute (RF) is situated in a typical agricultural district of Norway and has done much to automate the production of agricultural machinery produced in the neighbourhood. One of the manufacturers is Kverneland $\mathrm{A} / \mathrm{S}$, well known for their ploughs.

In plough production it is essential to get a smooth mould board to prevent soil sticking. The mould board is a double curved surface, and the aim is to achieve a surface quality with $\mathrm{Ra}<1.5 \mu \mathrm{m}$. The absolute dimension of the plough body is of no interest in the grinding process. 


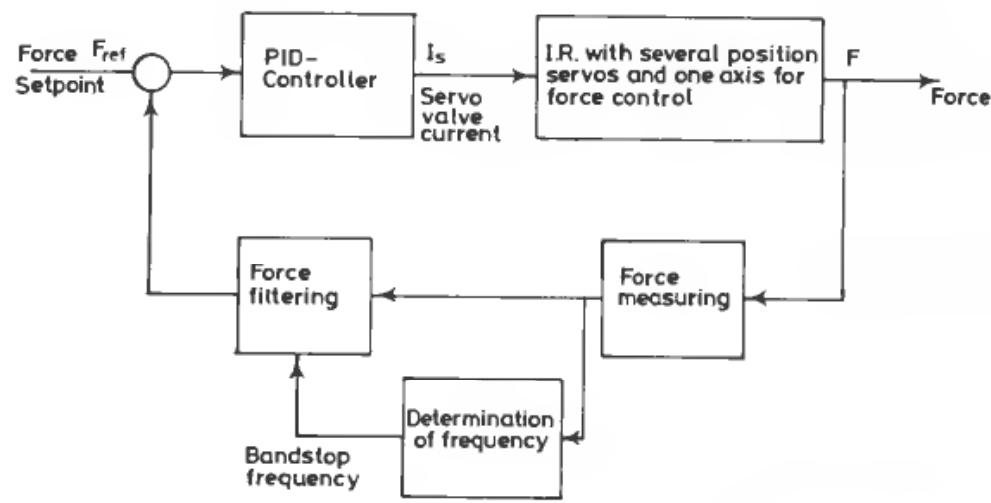

Figure 8. Force servo system of the automatic grinding machine.

Together with Kverneland A/S and NTNF, the Rogaland Research Institute started to develop an automatic grinding machine for plough bodies in 1977. Four years later the machine was finished and put in service. The grinding machine is a combination of a special purpose manipulator and a commercially available control system (TRALLFA). In order to achieve the necessary control of the grinding process, two of the five axes of the manipulator are controlled with force feedback when grinding is performed. As a plough handling device, all axis serve as position servos. The machine grinds two plough bodies at a time.

As a result of experiments it was found that the removal rate of metal in the grinding process is a function of the contact force between the work piece and the grinding belt, and the accumulated grinding time. The grinding machine measures both the time and the force. These inputs are the basis of the force control to assure a constant material removal rate during grinding. As the robot control system has a

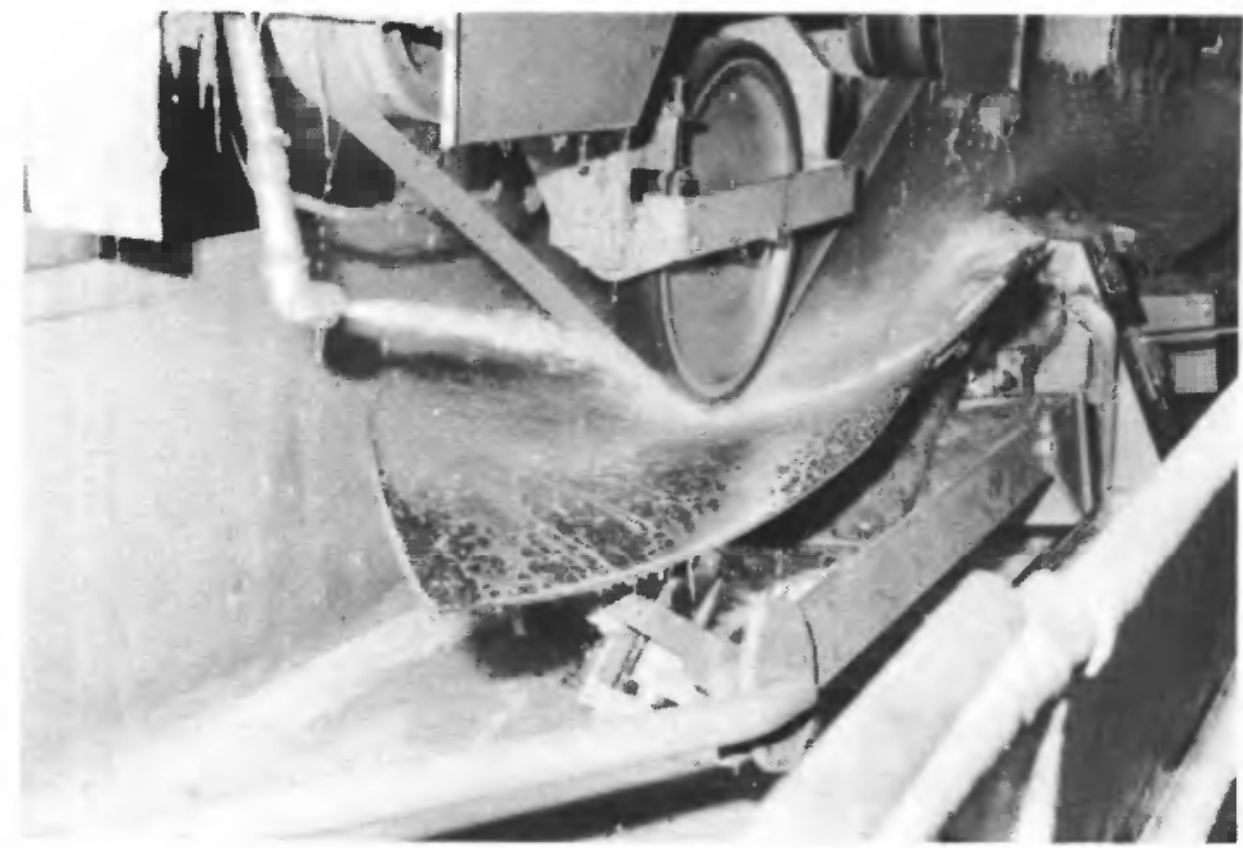

Figure 9. Close-up picture showing the belt grinding of a plough body. 
point-to-point programming option, this is used to teach the $x-y-z$ path of the grinding belt unit to follow the double curved surface fairly well.

Programming the grinding machine to grind a new type of plough takes typically three to four hours. This is acceptable because the repeatability of the machine is very good. At Kverneland A/S they have used the same programme for one and a half years, and productivity has increased considerably.

\subsection{Welding robot (SI)}

Stord Verft, one of the largest shipbuilding companies in Norway during the sixties and seventies, had rapid growth in the early seventies as there was a great

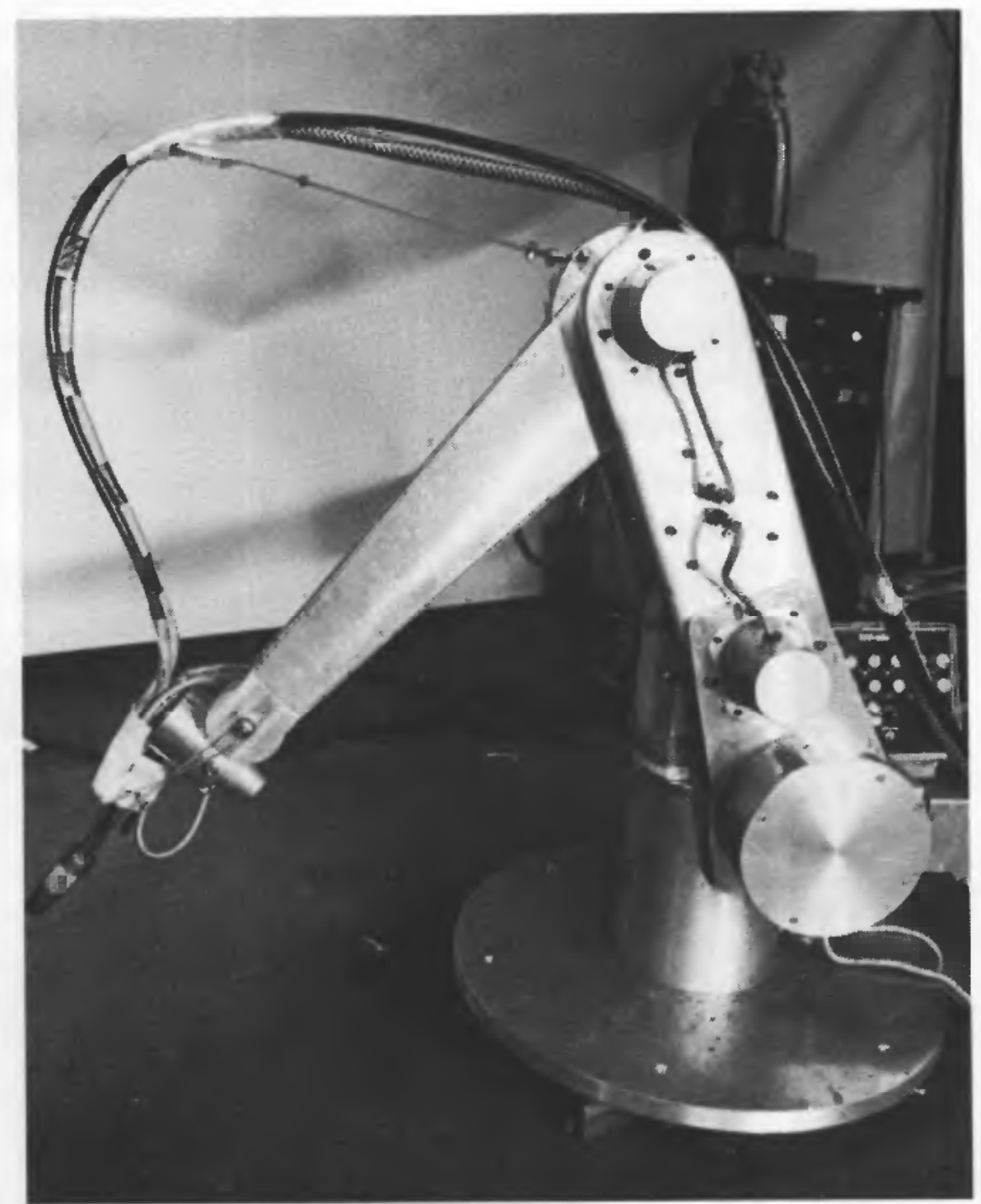

Figure 10. Stord Verft and Center for Industrial Research (SI) developed the first welding robot in Norway (1978). 
market for large tankers. Stord Verft automated the design and metal working shops by computer aided design (CAD) and computer controlled cutting equipment. What they didn't have was a seam welding machine, or robot.

In 1973 the Center for Industrial Research (SI) was engaged to develop a welding robot to be light enough to be moved anywhere in the metal factory. SI had previous experience in control systems from development of computer controlled cutting tables.

The welding robot which was finished in 1978 was powered by electric servos, and the manipulator had six degrees of freedom. The Kongsberg SM-4 microcomputer was selected for the control system. Compared with other robots at that time, the welding robot was quite advanced. The welding path was programmed by the point-to-point method from the handheld terminal. From this terminal it was possible to run the manipulator in cartesian coordinates. After teach-in of sufficient points on the welding path, the controller was able to make linear and circular interpolations between specific points. It was a simple and time saving programming system.

Stord Verft used the welding robot for some time, but unfortunately the crisis in the tanker market prevented further development and production.

\subsection{Computer controlled rock drilling machine (SI)}

More than half of Norway is rugged with mountains and valleys. Building roads requires that many hills have to be penetrated by tunnels. Tunnelling is a tedious and expensive process, and traditionally there is a low degree of automation.

In 1972 the Norwegian engineering and contracting company Ingeniør Thor Furuholmen $\mathrm{A} / \mathrm{S}$ started a development programme for automating tunnel drilling rigs. Even though microprocessor technology was unknown in tunnelling, the Center for Industrial Research (SI) was asked to make a control system using stateof-the-art microprocessor technology. To achieve maximum productivity in the drilling process, it was decided to make a three-boom manipulator with independent control of each boom.

After some difficulty in convincing the market of the value of this new technology, the first working prototype was produced and tested in 1978. Since then more than half a million metres of $45 \mathrm{~mm}$ holes have been drilled by the manipulator, including the under-sea tunnel to the island of Vardø in Northern Norway.

Among the most challenging parts of the project was design of the control system which had to be failsafe and easy to operate. Essential parts of the control system were:

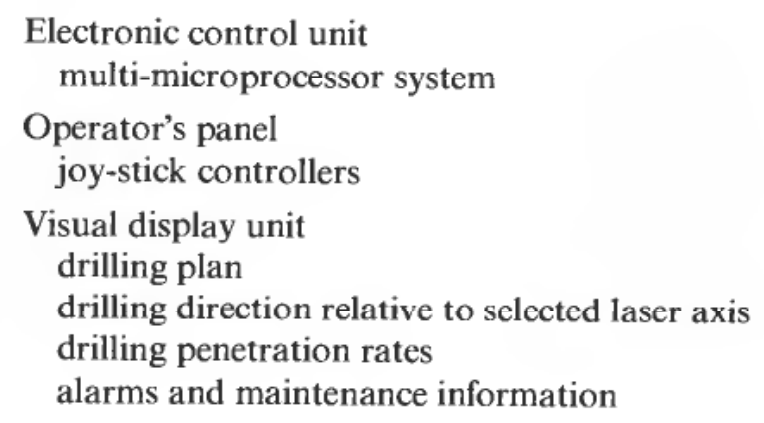


Sensor units

measuring boom positions, angles, pressures etc.

Hydraulic power pack

electrohydraulic controlling valves for controlling boom movements and drilling

Operation of the manipulator can be done in different ways:

Automatic positioning and drilling according to a preprogrammed drilling plan

Manipulator control, or the manual operation using the manipulator mode of the control system

Direct control is a standby level to ensure that the booms can be operated even if the control system fails

The real challenge during development was the automatic mode. In this mode the three booms will drill a complete pattern of holes according to a predefined drilling plan. On his VDU the drilling operator specifies the drilling plan by entering location, drilling direction and drilling depth of each hole. The pattern is displayed relative to the 'drilling $x y$-plan' on the VDU. When all holes are specified, the control system will take over and put the booms to work. During the drilling the supervisor may watch the progress of the drilling on his VDU.

A laser beam defines the true coordinate system inside the tunnel. To calibrate the position control of the booms, these are aligned with the beam and the position and orientation is measured. This calibration is used to transform coordinates of the local drilling $x y z$-system into exact drilling coordinates.

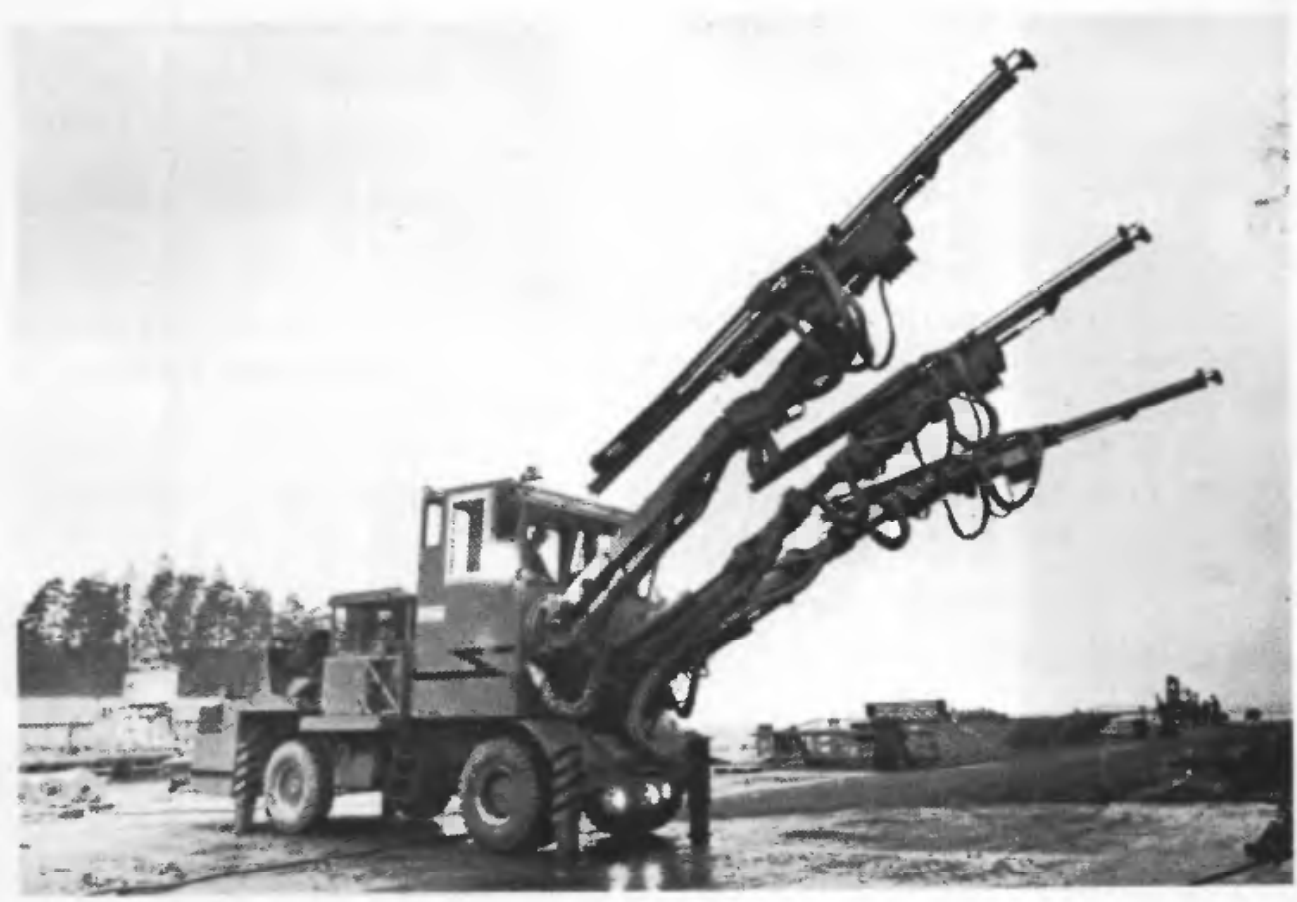

Figure 11. The computer controlled rock drilling machine developed by Ing. Thor Furuholmen A/S and Center for Industrial Research (SI). 


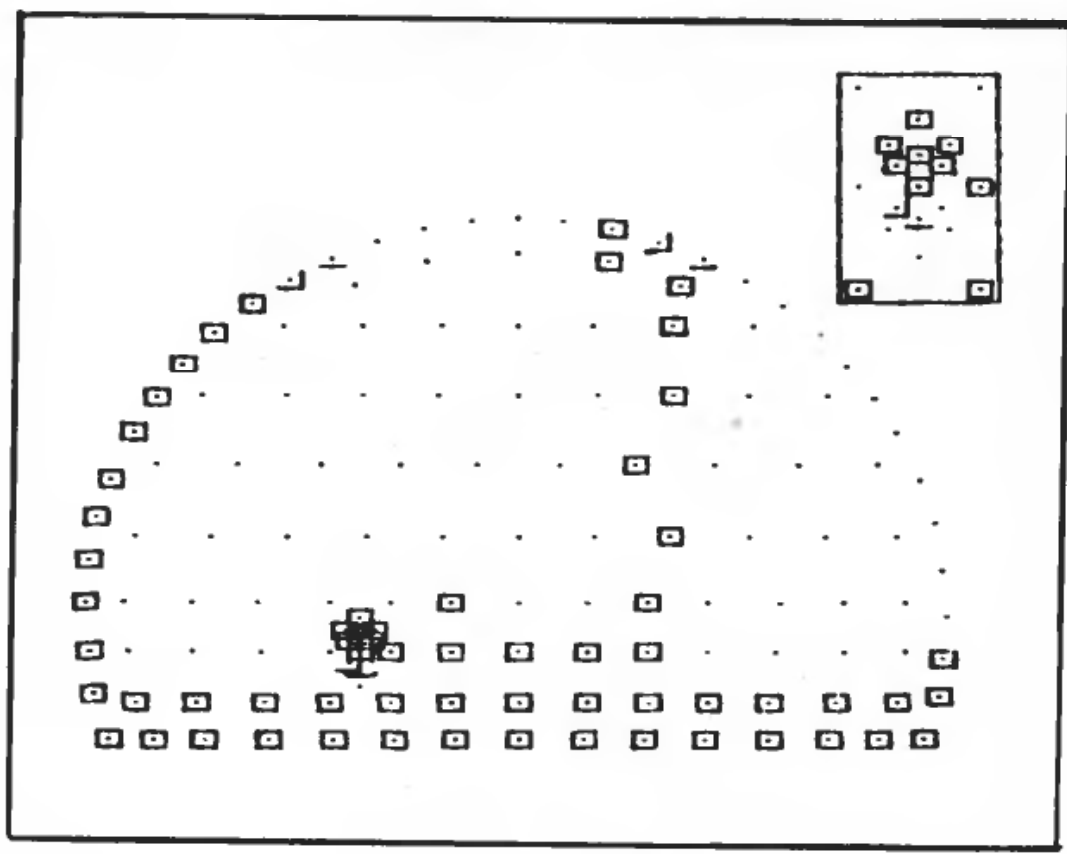

V.D.V. display in automatic mode.

(a)

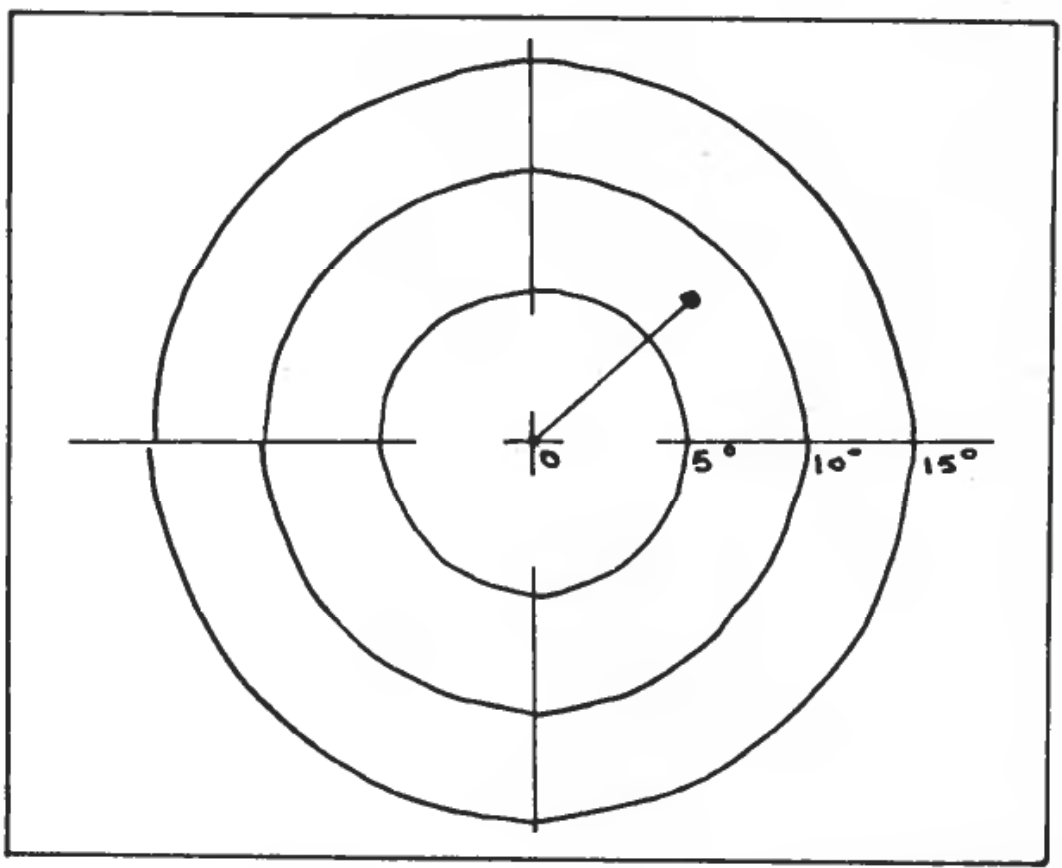

V.D.V. display in manipulator and direct modes.

(b)

Figure $12(a)$. The drilling plan is shown on the VDU. (b). On the VDU the operator can specify orientation and drilling depth of each hole. 
In the manipulator mode the booms are controlled by two 3-axis joysticks, onc for the position and one for the orientation. This mode is convenient to use when a manual override is necessary in automatic mode and also to establish the correct rig position parallel to the laser reference beam.

Ing. Thor Furuholmen $\mathrm{A} / \mathrm{S}$ has three manipulators working in Norway. Today the rig is produced under licence by three companies, Andersens Mekaniske Verksted $\mathrm{A} / \mathrm{S}$ in Flekkefjord (Norway), Perard Torque Tension Ltd. (England), and Tamrock (Finland).

The computer controlled rock drilling machine has demonstrated considerable cost savings in drilling. Other improvements have been achieved in operation, environment, precision, drilling pattern, drilling speed, maintenance and consumption of drilling equipment. Through this development project, SI gathered experience in designing electronic data equipment to be used in extremely hazardous environments. It also demonstrated a successful cooperation between a user company and a research institute.

\subsection{Real time multi-robot/multi-tasking control (SI)}

A well-known application of IRb is the handling of parts to and from machine tools. A time study of the time utilization of these IRb normally shows that robots are in action a few percent of the time. Since an IRb represents a large investment, it means that the profitability of the robot is not as good as it could be. One way to improve productivity is to let the robot take care of more tasks as handling parts to/from two or three machine tools.

The Norwegian robot manufacturer, Jonas Øglænd A/S, engaged the Center for Industrial Research (SI) to develop a system which could maximize throughput in a system where several robots could execute many tasks.

In 1982 the product called DSR (Data Systcm Robot) was finished. DSR is a general purpose control system for control of simple pneumatic driven manipulators, more complex servo controlled robots or any kind of automation equipment which needs to be controlled by time or sequence. The main modules of the system are:

real time multi-task monitor

programming and editing module

execution module (robot independent)

robot (equipment) driver module (robot dependent).

A Z80 microcomputer is used for the implementation of the DSR. The real-time monitor controls the execution of processes (task) by considering their priorities and available resources (robots etc.). If resources are free, the task with the highest priority will start to execute. If the resource is busy, the high priority process must wait until the resource becomes free. In addition to the control by priorities, it is possible to control periodic process.

Each part of the incoming conveyor is to be treated in both machine tools in order MI, then MII. There is a buffer area between MI and MII. The whole process can be regarded as two sub-processes, the service of MI and the service of MII. Servicing MI means moving the part from MI to the buffer and picking a new part from the feed conveyor. The MII process is to move the part from MII to the 


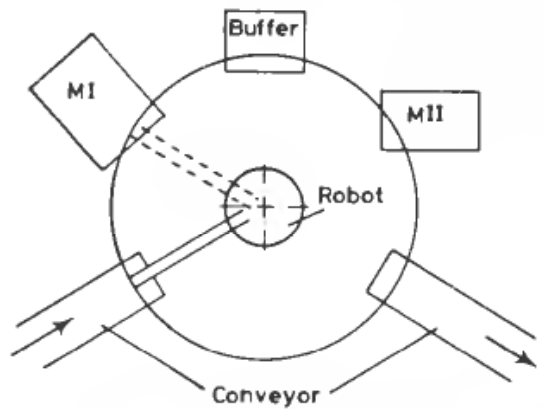

Figure 13. A possible but simple application of the DSR.

product conveyor and to feed MII with a part from the buffer. A simplified control sequence of the two processes in the DSR would be:

MI-sequence

Reserve robot

Move into MI

Pick part

Move to buffer

Leave part

Move to incoming conveyor

Pick a part

Move into MI

Leave part in $\mathrm{Ml}$

Go to free position

Release robot

Start machine MI

End
MII-sequence

Reserve robot

Move into MII

Pick part

Move to product conveyor

Leave part

Move to buffer

Pick a part

Move into MII

Leave part in MII

Go to free position

Release robot

Start machine MII

End

If MII stops by failure or for service, DSR allows MI to continue as long as parts are available on the incoming conveyor and the buffer is not full, and vice versa for MII if MI stops. DSR allows improvements such as handling a part directly from MI to MII if MII is waiting when MI has finished.

DSR has improved the productivity in the bicycle plant at Jonas Øglænd A/S in Norway. In some of the machining tasks, the time to change from one product to the next has been reduced from two hours to 20 minutes. Further developments in progress will interface DSR with other equipment such as electronic weighing (part control by weight) and other microcomputers. By use of DSR Øglænd is able to put standard machine tools into an overall control system to improve productivity and make safer the operation of machine tools.

\subsection{Underwater manipulator (SI)}

Future exploration of oil activities in the North Sea will take place in an ocean with climatic extremes and sea depths exceeding 300 metres. Due to production costs and safety considerations underwater production seems to be the alternative to bottom based rigs. For maintenance and inspection on deep sea production systems, remote operated vehicles with manipulators will replace human divers as much as possible. 
Developing useful underwater manipulator systems is a great challenge. In 1978 the Center for Industrial Research (SI) started a project together with the Norwegian Underwater Technology Center (NUTEC) in Bergen to develop a remote controlled manipulator to tackle complex operations under water. While NUTEC developed the tools, SI specified, designed and built the manipulator and control system. The overall project cost was about $7 \mathrm{MNOK}$, most of which was provided by NTNF.

The object of the project was to make a manipulator which had capabilities of performing operations like mounting bolts in holes, screwing/unscrewing nuts, steel cleaning, grinding. measurements etc. Tasks like these demanded a robot with a minimum of 6 degrees of freedom. Ingla AB in Sweden produced the arm which measured 1.6 metres fully extended. It was made of anodised aluminium and stainless steel with rotary hydraulic actuators in all 7 joints in addition to the gripper. The seventh joint was decoupled from the position computer control of the arm.

Modern microelectronics was used in the design of the computer control which was based on SIs extensive experience in the design of industrial robot control. Resolved motion control was selected as the most suitable for remote human control of the manipulator. All movements were controlled by means of three joysticks, one for control of position, one for orientation of the tool and one for the claw rotation. The advantage of using resolved motion control is obvious since movement of the joystick is directly coupled to the corresponding movement of the tool on the robot arm. How each joint is controlled to obtain the desired movement of the tool is of no interest to the operator. Translation of joystick operation to manipulator movement is done by coordinate transformations in a microprocessor.

Hardware modules for the control system are scparated in surface electronics and underwater electronics communicating through a RS422 high speed serial line. While coordinate transforms are computed by the surface microprocessor, the closed servo loop runs under water. All cables, both electric and hydraulic, are contained within the arm construction. This is a more expensive solution to manufacture, but there are great advantages since physical damage on the electro/hydraulic system is prevented.

Underwater operation of the manipulator is controlled by viewing through TVcameras mounted on and just behind the manipulator. The control system may adjust for the camera orientation so that 'forward' of the joystick refers to 'forward' in the picture seen by the operator.

Tools are necessary to use the manipulator in the sea. A market survey showed that very few tools specially designed for underwater manipulators were available. However, NUTEC provided some tools for the tests which were run in NUTEC's pool in 1981. These tools were of ordinary diver held types slightly modified to be handled by the manipulator. NUTEC also provided a submersible test rig for the tests which were run under water. Test arrangements and some test results are shown in Figure 14a and 14b.

In all, about 100 tests were logged with six different operators who had to control the manipulator by viewing through TV cameras. With a few exceptions most tasks came out quite well. One exception was grinding for NDT inspection of weld seams. Experience showed that it was impossible without any kind of force control of the tool. The time required to screw/unscrew bolts was typically 20 minutes. That is too long, and the use of special tools instead of a standard wrench socket would significantly have shortened the time. 


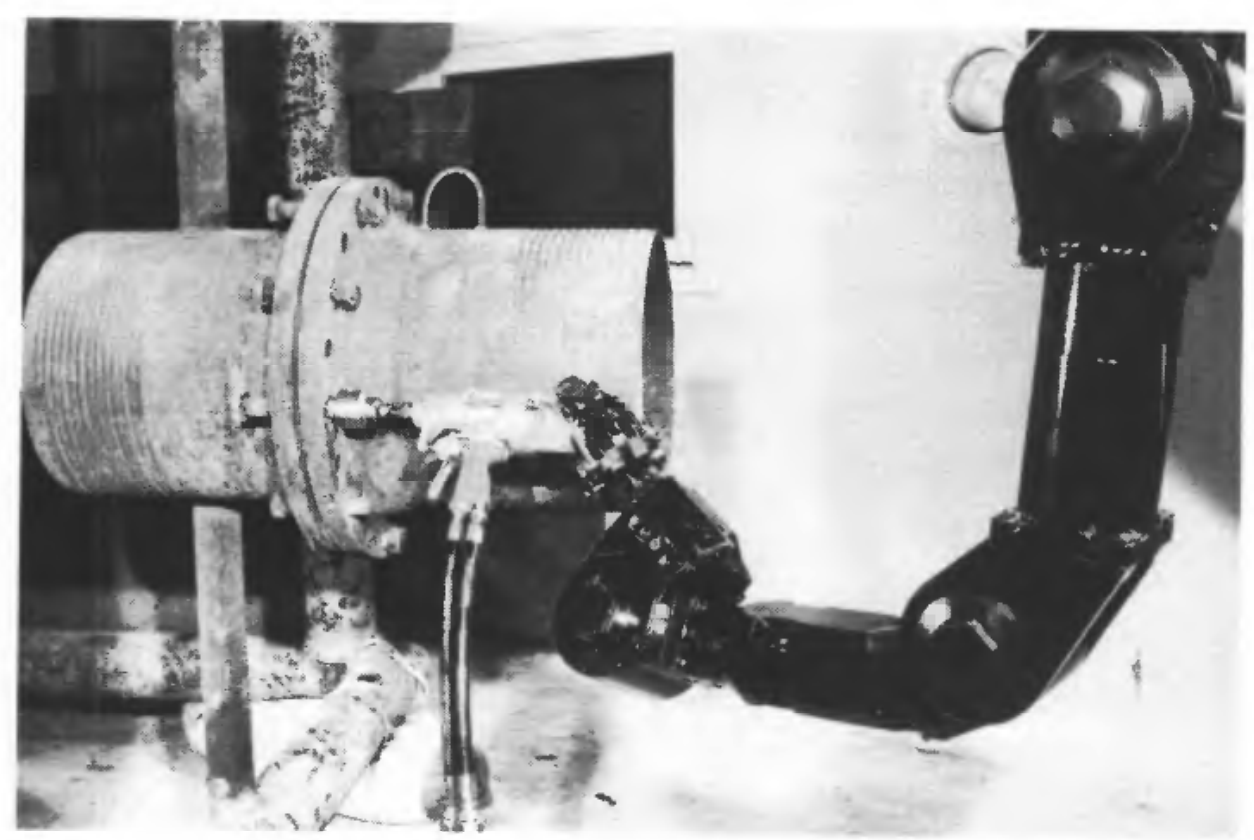

Figure 14a. Test arrangement with pool, manipulator and test rig.

\begin{tabular}{|c|c|c|c|}
\hline \multirow[b]{2}{*}{ Work task } & \multicolumn{2}{|c|}{ Succeeded } & \multirow[b]{2}{*}{ Comments } \\
\hline & Yes & No & \\
\hline $\begin{array}{l}\text { Steel cleaning with } \\
\text { water jet, sand } \\
\text { washing on steel }\end{array}$ & 4 & 0 & $\begin{array}{l}\text { Easy to manipulate, } \\
\text { reaction force no problem }\end{array}$ \\
\hline $\begin{array}{l}\text { Water jet cutting of } \\
\text { concrete, } P=700 \text { bar }\end{array}$ & 1 & 0 & $\begin{array}{l}30 \times 15 \mathrm{~cm} \text { cut in } 30 \mathrm{~min} \\
\text { Operator on land proved } \\
\text { only } 40 \% \text { better. }\end{array}$ \\
\hline Use of impact wrench & & & \\
\hline Screw on & 3 & 1 & Aver. time per nut: $15 \mathrm{~min}$ \\
\hline Screw off & 8 & 2 & Aver. time per nut: $10 \mathrm{~min}$ \\
\hline Brush-cleaning of weld & 6 & 0 & Need accurate manipulator \\
\hline Cut chain with grinder & 3 & 3 & Difficult \\
\hline Open/close valves $2^{\prime \prime}-4^{\prime \prime}$ & 9 & 3 & Aver. time per valve $\sim 20 \mathrm{~min}$. \\
\hline $\begin{array}{l}\text { Mount/dismount quick } \\
\text { hose couplings }\end{array}$ & 6 & 2 & Precision needed \\
\hline
\end{tabular}

Figure 14b. Some experiences from the test at NUTEC in 1981.

The mechanical design of the arm gave sufficient access to most operations. All six operators accepted the motion rate positioning control systcm combined with TV pictures. Poor tools were undoubtedly the most serious problem when running the tests. More powerful tools may be selected since the manipulator has more strength than a diver. Specially designed tools, together with good adaptors and tool racks, may change work from impossible to efficient. Force feedback and acoustic feedback would have been useful for some tasks.

In 1985 SI will probably start developing a new underwater manipulator based on the same concepts and experience from the first prototype. This project is sponsored by Norwegian companies. 


\subsection{Trallfa $T R-4000$ industrial robot concept}

The last generation of robots manufactured by Trallfa is the TR-4000 series. Technologically, the TR-4000 concept is far more advanced than its predecessor, the TR-3000. While the TR-3000 had a single-processor control system with most functions implemented in hardware, the TR-4000 is a multiprocessor, software based robot controller.

Trallfa has manufactured spray painting robots since 1969. Today Trallfa is going into other market areas such as path welding and handling. Spraying, welding and handling demand different manipulators with regard to work space, accuracy, speed and acceleration. This is now achieved by making different manipulators, all working with the same control system, the TR-4000. For Trallfa this concept allows faster development of new robots as only small modifications have to be made in the existing control system.

Inside the TR-4000 controller there are several microprocessors, each working with specialized functions such as servoing, disc $\mathrm{I} / \mathrm{O}$, operator communication, path control etc. One processor controls the communication on the main data/address bus to which all CPUs are connected. This flexible architecture means that other special purpose CPUs may be plugged into the system in order to improve the performance by new functions or high speed computation.

A vision module is one of the options that can be purchased. That module is able to recognize different parts which moves on a conveyor. Recognition is 2dimensional and works with binary pictures with 65000 pixels. These pictures are captured by a line scan camera and back-lighting of the object. The Trallfa Parts Identification System has memory to store data of 100 objects, each described with 16 features. A new object is learned just by passing it in front of the camera and assigning a name (number) to it. The operator does not have to give any 'intelligent' input.

In operation the Trallfa Parts Identification System will recognize the object and transmit the identification number to the robot controller which will then pick up the corresponding painting programme from the mass storage device. The hardware of the Parts Identification System includes a line scan camera, a light tube and two circuit boards which fit into the robot controller cabinet.

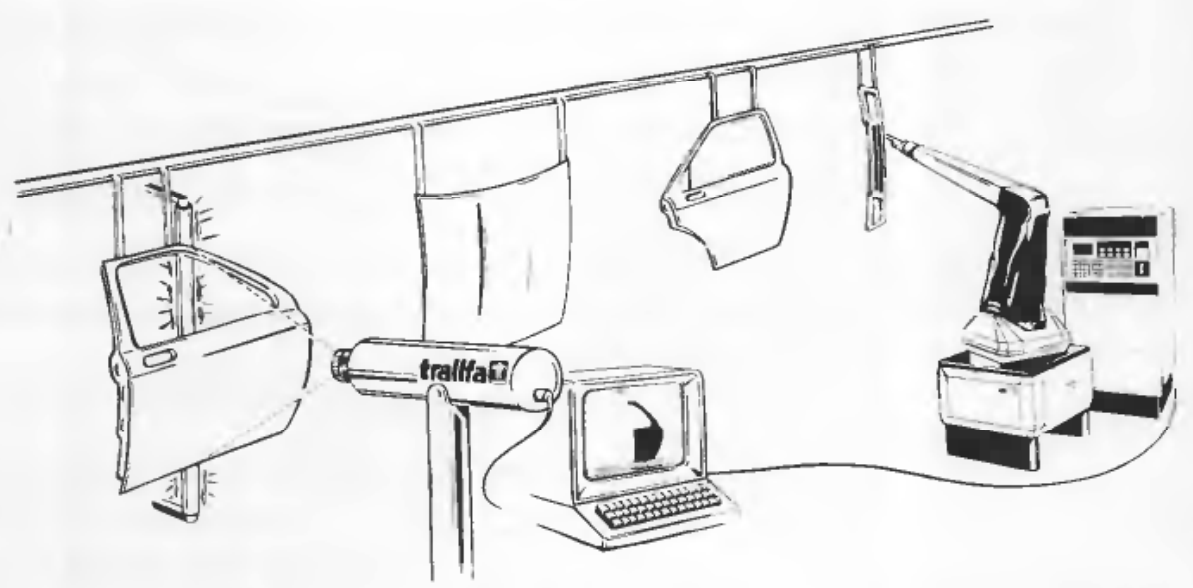

Figure 15. Trallfa Parts Identification System used for recognition of different parts in the automobile industry. 
One of the latest Trallfa developments is a coordinate conversion module. It converts robot coordinates into cartesian coordinates $(X, Y, Z)$. When the motions are controlled in the $X Y Z$-space, the speed can be calculated easily, and it is possible to achieve constant speed during movement. For certain applications, such as spray painting, constant speed of the tool means that the thickness of the coating will be constant.

In the future, cartesian path control makes possible an integration of CAD and robotics. A geometric product model describes a part in cartesian coordinates. Any process to be executed by the robot may be defined (programmed) relative to the $X Y Z$-description of the parts.

The cartesian coordinate module was important when General Motors made the largest purchase, at present, of Trallfa robots. Both the vision module and the cartesian coordinate module have been developed in cooperation with the Central Institute for Industrial Research.

\subsection{NORKYB-Norsk Kybernetikk A/S}

Norsk Kybernetikk is a new company established by Petter Gran-Jensen in 1983. The company is fast-growing and their first robot has already been demonstrated. NORK YB 800 has five or six degrees of freedom with an overall accuracy of $0.2 \mathrm{~mm}$. With an arm length of about $140 \mathrm{~cm}$, the maximum payload is $7 \mathrm{~kg}$. This robot is meant to be a low-cost alternative for small and medium size companies that need a robot for material handling or spray-painting.

The more advanced model NORKYB 1000 will be on the market in 1985. Model 1000 is twice as fast as model 500 and its payload is $10 \mathrm{~kg}$. Accuracy is said to be $1 / 1000 \mathrm{~mm}$ ! While model 500 has a control system with two microprocessors, NORKYB 1000 will be a multiprocessor system with eight to 16 microprocessors (16 bits) and bubble memory for program storagc. Most functions will be based upon adaptive algorithms with high-precision mathematics. As a consequence of cheaper but more powerful $\mu \mathrm{P}$ technology, the company's strategy is to let most of the robot control system be implemented in software.

The next development is a central controller to supervise the complete production system on the shop floor. It will communicate with robots, machinery, CAD-systems etc. and by using a mathematical model of the production line, the DARP (Data Assisted Robot Production) will control each robot and production machine.

\section{Conclusions}

Norway has two robot manufacturers and several institutes working with robot development and production. In a global view, some of these companies are working in the forefront of robot technology.

Trallfa $\mathrm{A} / \mathrm{S}$ is a market leader of spray painting robots. With an annual production of about 1500 robots, Trallfa is number 5 in the world compared with all other companies. While Trallfa has specialized in spray painting robots and Øglind in part handling manipulators, the research institutions have designed special purpose robots for new areas such as rock drilling and underwater maintenance. A close cooperation between manufacturers and R \& D institutes has led to a continuous development of new technology and control systems to keep the Norwegian robot industry among the most advanced in the world. 
So far, the R \& D institutes have also been a connecting link between robot users and IRb marketing companies in Norway. There is a lack of independent consultants who can assist companies to identify automation tasks, make a technical/economical analysis and suggest a solution including what kind of IR and automation equipment to use. R \& D institutes have tried to help companies with such problems, but the lack of industrial experience in R \& D institutes means that they are not familiar with the real problems on the shop floors.

A committee called KORO is working with an action plan to increase the use of robots in Norwegian industry. KORO consists of people from robot manufacturing companies, research institutes, universities and user companies. This plan will suggest how to bridge the gap between the potential user and the robot manufacturer or sales company. Additionally, KORO will try to establish more attractive rules for financial support so that even small companies with no experience within the field of robotics will get a chance to install their first robot. Financial support like this must be based on grants from NTNF or other government sources. 